\title{
Correction to: Changes in midge assemblages (Diptera Chironomidae) in an alpine lake from the Italian Western Alps: the role and importance of fish introduction
}

\author{
Selene Perilli • Paolo Pastorino - Marco Bertoli • Gianguido Salvi • \\ Filippo Franz $\cdot$ Marino Prearo $\cdot$ Elisabetta Pizzul
}

Published online: 25 May 2020

(C) Springer Nature Switzerland AG 2020

Correction to: Hydrobiologia (2020)

847:2393-2415

https://doi.org/10.1007/s10750-020-04257-3

Due to an unfortunate turn of events, some given names and family names were transposed in the original publication. The proper representation of the authors' names and their affiliations is published here.

Publisher's Note Springer Nature remains neutral with regard to jurisdictional claims in published maps and institutional affiliations.

The original article can be found online at https:// doi.org/10.1007/s10750-020-04257-3.

S. Perilli · P. Pastorino - M. Bertoli · F. Franz ·

E. Pizzul $(\bowtie)$

Department of Life Science, University of Trieste, via

Giorgieri 10, 34127 Trieste, Italy

e-mail:pizzul@units.it

P. Pastorino - M. Prearo

Experimental Zooprofilactic Institute of Piedmont,

Liguria and Valle d'Aosta, Via Bologna 148,

10154 Torino, Italy

G. Salvi

Department of Mathematics and Geosciences, University

of Trieste, Via Weiss 2, 34128 Trieste, Italy 